\title{
ANÁLISE DA CONECTIVIDADE DOS FRAGMENTOS NA BACIA HIDROGRÁFICA DO TIETÊ-JACARÉ
}

Connectivity analysis of fragments in the Tietê-Jacaré hydrographic basin

Recebido: $17 / 08 / 2018$

\section{Diego Peruchi Trevisan Luiz Eduardo Moschini}

\section{RESUMO}

A análise da fragmentação da paisagem é feita principalmente por meio de mapeamentos do uso e cobertura da terra, onde é possível identificar diferentes manchas e o grau de fragmentaçáo ou conectividade. Este trabalho tem o objetivo de analisar as conectividades estruturais da paisagem presentes no território da Bacia Hidrográfica do Tietê-Jacaré, por meio da aplicação dos Índices de conectividade estrutural da paisagem, com o intuito de avaliar o processo dinâmico e temporal dos fragmentos de vegetação natural de 2007 e 2017. As informaçóes foram analisadas por meio de Sistemas de Informação Geográfica (SIG) e índices métricos de conectividade e de fragmentação. Considerando o intervalo de 10 anos observou-se uma expansão das atividades agrícolas com um incremento de 24.507,53ha de áreas de cultivo e perda de áreas de vegetação nativa de 32.149 ha. Evidenciou-se também a diminuição do número de fragmentos, assim como o aumento do tamanho médio dos mesmos, derivados do crescimento das matrizes agrícolas com consequente diminuiçáo da diversificação de fragmentos das classes de uso e cobertura da terra. Os índices de fragmentação, ao expressarem o estado de configuração das paisagens, apresentaram-se como ferramentas importantes no diagnóstico voltado a conservação dos ecossistemas. Tais índices permitiram a comparação não apenas dos fragmentos naturais, mas de todas as classes de uso e cobertura da terra, o que é essencial no planejamento regional.

Palavras-chave: Análise da paisagem; Redes ambientais; Índices métricos de conectividade e de fragmentação; Bacia hidrográfica.

\section{ABSTRACT}

The analysis of landscape fragmentation is done mainly through land use mapping, where it is possible to identify different spots and the degree of fragmentation or connectivity. This work has the objective of analyzing the structural connectivity of the landscape present in the Tietê-Jacaré Hydrographic Basin, through the application of the structural connectivity indices of the landscape, with the purpose of evaluating the dynamic and temporal process of natural vegetation fragments of 2007 and 2017. The information was analyzed through Geographic Information Systems (GIS) and metric indexes of connectivity and fragmentation. Considering the interval of 10 years there was an expansion of agricultural activities with an increase of 24,507.53ha of cultivated areas and loss of native vegetation areas of $32,149 \mathrm{ha}$. It was also evidenced the decrease in the number of fragments, as well as the increase in the average size of the fragments, derived from the growth of the agricultural matrices with consequent reduction of the diversification of the fragments of the classes of use and land cover. Fragmentation indexes, when expressing the state of configuration of the landscapes, were presented as important tools in the diagnosis aimed at the conservation of ecosystems. These indices allowed the comparison not only of natural fragments, but of all classes of land use and land cover, which is essential in regional planning.

Keywords: Landscape analysis; Ecological Network; Metric indices connectivity and fragmentation; Hydrographic basin.

\section{INTRODUÇÃO}

A substituição de florestas nativas por outros usos da terra altera a configuração da paisagem, que assume a característica de um mosaico fragmentado
(GOERL et al., 2011). Tais substituiçôes sem um planejamento adequado para mitigação dos impactos podem gerar ecossistemas com baixa resiliência 
e resistência a distúrbios naturais ou antrópicos (ETTO et al., 2013).

As paisagens fragmentadas possuem um mosaico diversificado entre seus elementos, como os fragmentos e os corredores que exercem a função de conexão entre os elementos e a matriz (BOSCOLO et al., 2016). No processo de fragmentação, os remanescentes florestais muitas vezes ficam isolados e imersos em uma matriz antrópica, seja agrícola ou urbana, que pode ser inapropriada para a sobrevivência determinadas espécies (HADDAD et al., 2015).

O processo de fragmentação tem efeitos negativos sobre o padrão do uso do habitat, como redução de extensão original, o aumento no número de fragmentos de habitat, a diminuição no tamanho dos fragmentos e o aumento no isolamento dos fragmentos (FAHRIG, 2003). A fragmentação de habitats é uma das mais citadas causas da extinção das espécies e perda da diversidade biológica, sendo definida como o processo pelo qual uma área contínua de habitat é reduzida em tamanho e dividida em fragmentos separados por uma matriz diferente do original (D'EON et al., 2002).

A diminuição do tamanho dos fragmentos aumenta a influência do perímetro-área, o chamado efeito de borda, que proporciona entre os principais impactos negativos as mudanças microclimáticas, o aumento da atividade dos predadores nas bordas, o aumento da mortalidade de espécies devido às condiçôes desfavoráveis do ambiente da matriz e maior probabilidade de invasão de espécies exóticas (CHALFOUN et al., 2002).

A diminuição da conectividade limita a dispersão dos organismos, causando consequências negativas nas populaçóes já que reduz o fluxo genético, podendo em grande escala levar a perda de diversidade genética (GIBBS; STANTON, 2001). Em ambientes degradados, a restauração florestal é essencial como forma de recuperar e aumentar a conectividade entre os fragmentos e consequentemente promover os serviços ecossistêmicos essenciais para a conservação e manutenção dos ecossistemas (FAHRIG, 2002; MONTEIRO et al., 2016).

Os estudos envolvendo os processos de conectividade entre fragmentos e os fluxos ecológicos têm sido considerados como prioritários na investigação da ecologia da paisagem (WU; ROBBS; 2002).
Atualmente, a análise da fragmentação da paisagem é feita principalmente por meio de mapeamentos do uso e cobertura da terra, onde é possível identificar diferentes manchas e determinar o seu grau de fragmentaçáo ou conectividade (CALEGARI et al., 2010).

As mudanças ocorridas em uma paisagem, assim como a análise dos padróes da fragmentação florestal podem ser estudadas por meio da avaliação de índices ou métricas da paisagem para caracterização quantitativa e qualitativa, que permitem também, comparar paisagens, identificar diferenças e determinar relaçóes entre os processos funcionais e os padróes dessas paisagens (CABACINHA et al., 2010; SILVA; SOUZA, 2014).

Por meio da análise de mapeamentos realizados com dados de sensores orbitais de diferentes épocas ou anos, é possível analisar a evolução e dinâmica da fragmentação da paisagem. Neste contexto as ferramentas de geoprocessamento e análises estatísticas a partir de mapeamentos de uso e cobertura da terra auxiliam na avaliação do grau de fragmentação ou conectividade da paisagem (GOERL et al., 2011).

Diante dessas consideraçóes, este trabalho tem o objetivo de analisar as conectividades estruturais da paisagem presentes no território da Bacia Hidrográfica do Tietê-Jacaré, por meio da aplicação dos Índices de conectividade estrutural da paisagem, com o intuito de avaliar o processo dinâmico e temporal dos fragmentos de vegetaçáo natural de 2007 e 2017.

\subsection{MATERIAL E MÉTODOS}

\section{ÁREA DE ESTUDO}

As Leis Estaduais n.7.663, de 30/12/91 (SÃO PAULO, 1991) e n.9.034 de 27/12/1994 (SÃO PAULO, 1994) instituem o gerenciamento de recursos hídricos no estado de Sáo Paulo que passou a ser realizado por meio de Unidades de Gerenciamento de Recursos Hídricos (UGRHIs). O estado possui atualmente 22 UGRHIs que foram delimitadas a partir do conceito de bacia hidrográfica, segundo o qual cada unidade engloba os recursos hídricos que convergem para um corpo d'água principal, necessitando de articulação entre pesquisa, gerenciamento e aplicação de inovaçóes (COMITÊ DAS BACIAS HIDROGRÁFICAS DA SERRA DA MANTIQUEIRA, 2015). 
A Figura 1 destaca a unidade de gestão número 13, a Bacia Hidrográfica do Tietê-Jacaré, com área total de $11.810,9 \mathrm{~km}^{2}$, englobando 37 municípios. A bacia hidrográfica está localizada no centro do estado de São Paulo, entre

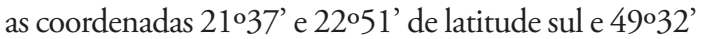

e 47030' de longitude oeste. Com área de drenagem de $11.749 \mathrm{~km} 2$ a Bacia Hidrográfica do Tietê-Jacaré engloba três rios principais (Rio Tietê, o Rio Jacaré-Guaçu e o Rio Jacaré Pepira) e os reservatórios de Bariri, Ibitinga e Carlos Botelho (Lobo/Broa) (TUNDISI et al., 2008).

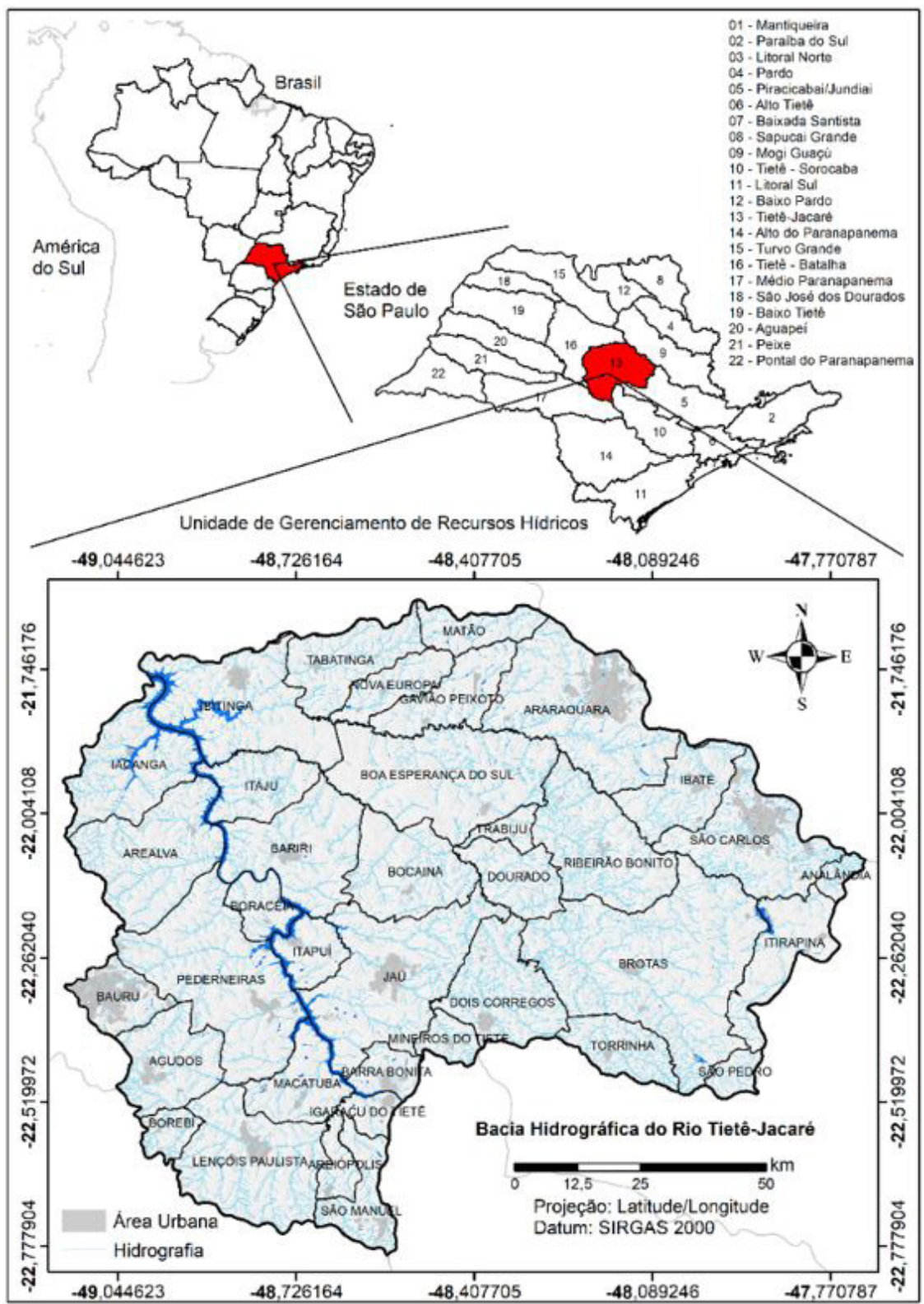

Figura 1 - Localização geográfica da Bacia Hidrográfica do Tietê-Jacaré. 
O clima pela classificação de Köppen-Geiger, situa-se entre clima tropical úmido (de outubro a março) e inverno seco (de abril a setembro). O relevo é variável, com o ponto máximo de altitude a $1060 \mathrm{~m}$ na região de São Carlos. A unidade Tietê-Jacaré está na Depressão Periférica do estado de São Paulo onde se encontram os aquíferos Bauru, Serra Geral e Botucatu. Em sua maioria, a bacia é formada por solos de areias quartzosas profundas a moderadas e em menores quantidades ocorre a presença de Latossolo Roxo Eutrófico (TUNDISI et al., 2008).

As principais atividades econômicas estão ligadas principalmente à agroindústria como produção de açúcar, álcool e processamento de cítricos. Nos maiores municípios como Bauru, São Carlos, Araraquara e Jaú, outros setores industriais como papel, bebidas, calçados e metal mecânica também se destacam (TUNDISI et al., 2008).

A região conta com as Unidades de Conservação regulamentadas pela lei federal $n^{\circ 9.985}$, de 18 de julho de 2000: Área de Proteção Ambiental Corumbataí, Botucatu e Tejupá; Área de Proteção Ambiental Ibitinga; Estação Ecológica Sebastião Aleixo da Silva; Estação Ecológica de Itirapina; Estação Ecológica Mata do Jacaré; Floresta Estadual de Pederneiras; Reserva Particular do Patrimônio Natural Reserva Ecológica Amadeu Botelho e Reserva Particular do Patrimônio Natural Olavo Egydio Setubal. Apresentando $1.106 \mathrm{~km}^{2}$ de vegetação natural remanescente que ocupa, aproximadamente, $9 \%$ da área da bacia, com maiores ocorrências de Floresta Estacional Semidecidual e Savana (TUNDISI et al., 2008).

Por apresentar características de desenvolvimento consolidadas, que integram municípios com elevado grau de urbanização e potenciais industriais e agrícolas, que necessitam de uma rede viária integrada e consequentemente de uma rede hidrológica que comporte todo esse desenvolvimento, a Bacia Hidrográfica do Tietê-Jacaré torna-se uma área potencial para análise das relaçóes de conectividade entre os compartimentos da paisagem e suas inter-relaçóes com o desenvolvimento antrópico e as áreas naturais, avaliando como estes influenciam na conservação dos ecossistemas.

\subsection{METODOLOGIA}

As informações foram inseridas e analisadas em Sistemas de Informaçóes Geográficas (SIGs), sendo utilizado o software ArcGis 10.5. Para a caracterização da paisagem, foi elaborado um banco de dados georreferenciado da Bacia Hidrográfica do Tietê-Jacaré, utilizando-se a projeção geográfica latitude/longitude, datum SIRGAS2000 para todo o plano de informação.

As informaçóes utilizadas para a delimitação da Bacia Hidrográfica do Tietê-Jacaré foram obtidas da base de dados digital do Instituto Brasileiro de Geografia e Estatística (IBGE), malha digital dos municípios brasileiros versão 2015. Esse arquivo foi importado para o Sistema de Informação Geográfica, que possibilitou a análise e processamento digital do arquivo vetorial, sendo utilizadas as cartas planialtimétricas folhas (INSTITUTO BRASILEIRO DE GEOGRAFIA E ESTATÍSTICA, 1971): SF-22-X-D-IV-2; SF-22-X-DIV-4; SF-22-X-D-V-1; SF-22-X-D-V-2; SF-22-X-D-V-3; SF-22-X-D-V-4; SF-22-X-D-VI-1; SF-22-X-D-VI-2; SF-22-X-D-VI-3; SF-22-X-D-VI-4; SF-22-Z-B-I-2; SF-22-Z-B-I-4; SF-22-Z-B-II-1; SF-22-Z-B-II-2; SF-22-Z-B-II-3; SF-22-Z-B-II-4; SF-22-Z-B-III-1; SF-22-Z-B-III-2; SF-22-Z-B-III-3; SF-22-Z-B-III-4; SF-22-Z-B-IV-2; SF-22-Z-B-V-1; SF-22-Z-B-V-2; SF-22-Z-B-V-3; SF-22-Z-B-V-4; SF-23-V-C-IV-3; SF-23-Y-A-I-1; SF-23-Y-A-I-2; SF-23-Y-A-I-3; SF23-Y-A-IV-1, referentes à área de estudo e adquiridas em meio analógico na escala 1:50.000.

\section{USO E COBERTURA DA TERRA DA BACIA HIDROGRÁFICA DO TIETÊ-JACARÉ}

A classificação do uso e cobertura da terra para os anos de 2007 e 2017 foi baseada no sistema multinível de classificação proposto pelo Manual Técnico de Uso da Terra (INSTITUTO BRASILEIRO DE GEOGRAFIA E ESTATÍSTICA, 2013), que no nível hierárquico primário (I) (Tabela 1) contemplou quatro classes que indicaram as principais categorias da cobertura terrestre, as quais foram discriminadas com base na interpretaçáo dos dados dos sensores remotos, numa escala mais ampla.

O nível hierárquico secundário (II) explicitou os tipos de usos inseridos no primeiro nível com um detalhamento mais apurado da cobertura e o uso da terra em uma escala local e posteriormente 
Tabela 1 - Descrição das classes de uso e cobertura da terra.

\begin{tabular}{l|l|l}
\hline \multicolumn{1}{c|}{ Classe (I) } & \multicolumn{1}{|c}{ Tipo (II) } & \multicolumn{1}{c}{ Descrição (III) } \\
\hline $\begin{array}{l}\text { Área Antrópica } \\
\text { não Agrícola }\end{array}$ & Áreas urbanizadas & $\begin{array}{l}\text { Área de adensamento urbano e áreas com instalaçóes rurais (industriais e } \\
\text { domiciliares }\end{array}$ \\
\hline \multirow{4}{*}{$\begin{array}{l}\text { Área Antrópica } \\
\text { Agrícola }\end{array}$} & Cana-de-açúcar & Área de cultivo de Saccharum officinarium L. \\
\cline { 2 - 3 } & $\begin{array}{l}\text { Citricultura e } \\
\text { culturas diversas }\end{array}$ & Área de cultivo de Citros sinensis, Zea mays, Coffea arabica L. e Oryza sativa. \\
\cline { 2 - 3 } & Pastagens & $\begin{array}{l}\text { Área com predomínio de vegetação herbácea (nativa ou exótica), utilizada } \\
\text { para pecuária extensiva. }\end{array}$ \\
\cline { 2 - 3 } & Silvicultura & Área de cultivo homogêneo de Eucalyptus spp ou Pinus spp.. \\
\cline { 2 - 3 } & Solo exposto & Área de pousio do solo para cultivo de Saccharum officinarium L. \\
\hline \multirow{2}{*}{$\begin{array}{l}\text { Vegetação } \\
\text { Natural }\end{array}$} & Vegetação Nativa & $\begin{array}{l}\text { Área com predomínio de vegetação arbustiva/arbórea, com as formaçôes } \\
\text { vegetais de Floresta Estacional Semidecidual e Cerradão. }\end{array}$ \\
\hline Água & Corpos hídricos & Rios de grande porte, lagos, lagoas e represas. \\
\hline
\end{tabular}

o nível hierárquico terciário (III) explicitou os usos propriamente ditos.

\section{DINÂMICA DO USO E COBERTURA DA TERRA DA BACIA HIDROGRÁFICA DO TIETÊ-JACARÉ}

A dinâmica temporal do uso e cobertura da terra foi realizada com base na classificação visual das imagens LandSat disponíveis na plataforma do United States Geological Survey (2017), datadas em 21 de abril de 2007 e 11 de março de 2017. Por meio da digitalização em tela foi realizada a atribuição de um "pixel" a cada classe de uso.

Para análise do uso e cobertura da terra do ano de 2017, foram utilizadas imagens do satélite LandSat 8 - sensor OLI/TIRS, bandas 6,5,4, e para o ano de 2007 foram utilizadas imagens do satélite LandSat 5 - sensor TM, bandas 5,4,3, referentes às órbitas/pontos 220/75, 220/76 e 221/75, 221/76. A utilização de cenas de satélites diferentes ocorreu em virtude da indisponibilidade de imagens por um único satélite no período de estudo. As cenas utilizadas para este estudo foram trabalhadas na mesma resolução espacial de 30 metros.

A utilização de cenas de satélites diferentes ocorreu em virtude da indisponibilidade de imagens por um único satélite no período de estudo, as cenas utilizadas para este estudo possuíram a mesma resolução espacial de 30 metros. As datas foram selecionadas de acordo com o cronograma de trabalho a ser realizado, onde os períodos de março e abril, em decorrência da sazonalidade das práticas agrícolas predominantes na região. A diferença de 10 anos entre as imagens possibilitou o estudo dos padróes temporais da paisagem, essenciais no direcionamento do planejamento regional, o qual considerou as vertentes de crescimento e desenvolvimento presentes.

\section{ANÁLISE DA REDE ESTRUTURAL DA PAISAGEM DA BACIA HIDROGRÁFICA DO TIETÊ-JACARÉ}

Para análise da conectividade estrutural da paisagem foram utilizados índices métricos de conectividade e de fragmentação adaptados de McGarigal e Marks (1995), Volotão (1998), Goerl et al. (2011) e Rempel et al. (2012). Foram consideras as interferências e as correlaçôes das áreas naturais com o espaço viário e hidrológico analisadas a partir das informaçóes presentes na caracterização do uso e cobertura da terra pelas imagens do satélite LandSat 5 e 8 de 2007 e 2017 respectivamente.

Diversos autores vêm desenvolvendo trabalhos relacionados à conectividade estrutural da paisagem (MEDINI; VIEIRA, 2007; GUIMARĀES, 2009; EUROPARC, 2009; GOERL et al., 2011; MADUREIRA, 2012; LORONI, 2015; MONTANHEIRO; KIANG, 2016; ADAMCZYK, J; TIEDE, 2017), principalmente relacionados a criação de corredores ecológicos e deslocamento de espécies. 
O estudo realizado por Madureira (2012) abordou o conceito de infraestrutura verde na paisagem urbana contemporânea e o desafio da conectividade e da oportunidade da multifuncionalidade. $\mathrm{O}$ trabalho teve o objetivo de apresentar, desenvolver e discutir o conceito de infraestrutura e conectividades verdes, discutindo sobre o desafio da conectividade das áreas verdes urbanas enquanto valor ecológico, social e de composição urbana.

Para o estudo da rede estrutural da paisagem da Bacia Hidrográfica do Tietê-Jacaré, com índices métricos de conectividade e de fragmentação estrutural da paisagem considerou-se que quanto mais fragmentada a paisagem, menor a conectividade entre os seus elementos, sobretudo em relação a processos de origem hidrológica e geomorfológica (GOERL et al., 2011).

O uso e cobertura da terra é um dos indicadores mais utilizados para determinar o grau de fragmentação de uma área de estudo ou de uma bacia hidrográfica. Desta forma, foram elaborados índices (Tabela 2) com base em atributos do uso e cobertura da terra, calculados através da função "Raster Calculator" e do Plugin "Patch Analyst" (REMPEL et al., 2012) no ArcGis 10.5.

Ac = área de cada classe; Af = área do fragmento; Afc = área do fragmento da classe; At = área total; $\mathrm{Cf}=$ Comprimento do fragmento $\mathrm{Cf} \mathrm{c}=$ Comprimento dos fragmentos por classe; DP = densidade do perímetro; $\mathrm{DPc}=$ densidade do perímetro por classe; DesvP = Desvio padrão; Fax = área média dos fragmentos; Faxc = área média dos fragmentos por classe; Fmax = maior fragmento da bacia; Fmaxc $=$ maior fragmento da classe $;$ nc $=$ número de classes; IF = Índice de forma; IFc= Índice de forma por classe $\mathrm{Nf}=$ fragmentos totais; $\mathrm{Nfc}=$ fragmentos de cada classe; $\mathrm{P}=$ perímetro; $\mathrm{Sxc}=$ declividade média da classe; $\mathrm{Sxt}=$ declividade média.

Os índices de fragmentação da paisagem calculados para a área de estudo foram separados em dois grupos principais, os indicadores gerais e os indicadores relativos da fragmentação. Assim, os indicadores gerais foram os índices calculados considerando inteiramente a bacia hidrográfica como unidade de análise, permitindo a comparação e avaliação das condiçóes de fragmentação e conectividade entre bacias e sub-bacias distintas (MADUREIRA, 2012).
Os indicadores relativos foram as métricas estabelecidas para as classes de usos e cobertura da terra encontradas na bacia hidrográfica, permitindo a elaboração de uma análise comparativa entre as classes de uso e possibilitando uma avaliação do comportamento da bacia frente a impactos causados pela ocorrência de processos de qualquer natureza (OLIVEIRA et al., 2004), como por exemplo, por intermédio da análise do indicador Declividade Média por Classe de uso e cobertura da terra foi possível determinar a capacidade potencial dos fragmentos de cada classe se conectar com os fragmentos à jusante (GOERL et al., 2011).

\subsection{RESULTADOS E DISCUSSÓES}

\section{DINÂMICA TEMPORAL DE USO E COBERTURA DA TERRA DOS ANOS DE 2007 E 2017 DA BACIA HIDROGRÁFICA DO TIETÊ-JACARÉ}

Foram identificados nove (9), tipos de uso e cobertura da terra para os anos de 2007 e 2017 (Figura 2), sendo classificados os usos de cana-de-açúcar, corpos hídricos, citricultura, culturas diversas (pela resoluçáo das imagens de satélites, algumas regióes como cultivo de milho, café e arroz foram agrupadas no mesmo tipo de uso), pastagens, silvicultura, áreas urbanizadas e vegetação nativa.

Considerando o intervalo de 10 anos observou-se uma expansão das atividades agrícolas com um incremento de $24.507,53 \mathrm{ha}(2,05 \%$ da área total) de áreas de cultivo, principalmente pela cultura de cana-de-açúcar. Este valor é pequeno ao considerar-se o tamanho total da Bacia Hidrográfica do Tietê Jacaré, entretanto está baixa modificação corrobora com o estado de consolidação das atividades antrópicas na região, onde os usos e as regióes cuja as atividades agrícolas ocorrem, já estão pré-definidas.

Para o ano de 2007 , aproximadamente $72 \%$ da área de estudo apresentou o predomínio das atividades agrícolas sendo 542.124 ha ocupados pela cana-de-açúcar, 49.272,60ha por silvicultura, 76.817,59ha por pastagens, $62.121,90$ ha pela citricultura e $1.315,71$ por culturas diversas como milho, café e arroz (Tabela 3).

As áreas de solo exposto estão associadas às práticas agrícolas (122.046ha), pois as mesmas referem-se ao período de pousio e preparo do solo para a próxima 
Tabela 2 - Índices para avaliação do grau de fragmentação e conectividade da paisagem.

\begin{tabular}{|c|c|c|c|}
\hline Índice & Equação & Unidade & Descrição \\
\hline Área média dos fragmentos por classe & $\mathrm{F}_{c x}=\frac{A_{c}}{N_{f c}}$ & ha & $\begin{array}{l}\text { Tamanho médio dos fragmentos por } \\
\text { classe }\end{array}$ \\
\hline Área total & At $=\sum A f$ & ha & $\begin{array}{l}\text { Tamanho médio dos fragmentos por } \\
\text { classe }\end{array}$ \\
\hline Área média dos fragmentos & $\mathrm{F}_{\mathrm{ax}}=\sum \frac{A_{f}}{N_{f}}$ & ha & Tamanho total dos fragmentos \\
\hline Área total dos fragmentos por classe & $\mathrm{Ac}=\sum A f_{c}$ & ha & $\begin{array}{l}\text { Tamanho total dos fragmentos por } \\
\text { classe }\end{array}$ \\
\hline Área relativa ocupada & $A R O=\frac{\frac{A_{c}}{N_{f_{c}}}}{\frac{A_{t}}{N_{f}}}$ & - & $\begin{array}{l}\text { Valor referente à o quanto cada classe } \\
\text { ocupa em relaçáo a área total }\end{array}$ \\
\hline Declividade média & $S=\sum \frac{S_{x t}}{N_{f t}}$ & o & Valor da declividade média \\
\hline Declividade média por classe & $S=\sum \frac{S_{x c}}{N_{f c}}$ & o & Valor da declividade média por classe \\
\hline Densidade de fragmentação & $\mathrm{F}_{\mathrm{d}}=\frac{N_{f}}{A_{t}}$ & $\mathrm{~N}_{\mathrm{f}} / \mathrm{ha}$ & $\begin{array}{l}\text { Número de fragmentos em relação } \\
\text { a área }\end{array}$ \\
\hline $\begin{array}{l}\text { Densidade de fragmentação por } \\
\text { classe }\end{array}$ & $F_{d c}=\sum \frac{N_{f c}}{A_{c}}$ & $\mathrm{~N}_{\mathrm{f}} / \mathrm{ha}$ & $\begin{array}{l}\text { Número de fragmentos em relação a } \\
\text { área por classe }\end{array}$ \\
\hline Densidade do perímetro (borda) & $\mathrm{DP}=\frac{P}{A t}$ & $\mathrm{~m} / \mathrm{m}^{2}$ & $\begin{array}{l}\text { Relação do perímetro com a área } \\
\text { total }\end{array}$ \\
\hline $\begin{array}{l}\text { Densidade do perímetro (borda) por } \\
\text { classe }\end{array}$ & $\mathrm{DPc}=\frac{P c}{A t c}$ & $\mathrm{~m} / \mathrm{m}^{2}$ & $\begin{array}{l}\text { Relação do perímetro com a área } \\
\text { total por classe }\end{array}$ \\
\hline $\begin{array}{l}\text { Desvio padrão da área média dos } \\
\text { fragmentos }\end{array}$ & $\operatorname{DesvP}_{\mathrm{Fax}}=\frac{\sqrt{A f-F a x^{2}}}{N f c}$ & ha & $\begin{array}{l}\text { Variaçáo do tamanho das manchas } \\
\text { sob o valor médio }\end{array}$ \\
\hline $\begin{array}{l}\text { Desvio padrão da área média dos } \\
\text { fragmentos por classe }\end{array}$ & $\operatorname{DesvP}_{\mathrm{Fax}}=\frac{\sqrt{A f c-F a x c^{2}}}{N f c}$ & ha & $\begin{array}{l}\text { Variação do tamanho das manchas } \\
\text { sob o valor médio por classe }\end{array}$ \\
\hline Indicador médio de forma & $\mathrm{IF}=\frac{P}{A t^{2}}$ & $\mathrm{~m} / \mathrm{m}^{2}$ & \multirow{2}{*}{$\begin{array}{l}\text { Expressa o quanto a mancha é } \\
\text { próxima de um círculo. Quanto mais } \\
\text { próximo de } 1 \text { for o valor, a forma } \\
\text { da mancha é mais parecida com um } \\
\text { círculo. }\end{array}$} \\
\hline Indicador médio de forma por classe & $\mathrm{IFc}=\frac{P}{A c^{2}}$ & $\mathrm{~m} / \mathrm{m}^{2}$ & \\
\hline Índice de maior fragmento & $\mathrm{F}_{\mathrm{m}}=\frac{F \max }{A_{t}} \times 100$ & $\%$ & $\begin{array}{l}\text { Relação do maior fragmento com a } \\
\text { área total }\end{array}$ \\
\hline Índice de maior fragmento por classe & $\mathrm{F}_{\mathrm{m}}=\frac{F \max c}{A_{t} c} \times 100$ & $\%$ & $\begin{array}{l}\text { Relaçáo do maior fragmento com a } \\
\text { área total por classe }\end{array}$ \\
\hline Média de fragmentos & $\mathrm{F}_{\mathrm{x}}=\frac{N_{f}}{N_{c}}$ & - & Média do número de fragmentos \\
\hline Número total de fragmentos & $N_{f}=\sum N_{f c}$ & - & Número total de fragmentos \\
\hline Perímetro médio (borda) & $\mathrm{P}=\sum \frac{C f}{N f}$ & $\mathrm{~m}$ & Comprimento médio do perímetro \\
\hline Perímetro (borda) médio por classe & $\mathrm{P}=\sum \frac{C f c}{N f}$ & $\mathrm{~m}$ & $\begin{array}{l}\text { Comprimento médio do perímetro } \\
\text { por classe }\end{array}$ \\
\hline
\end{tabular}

Fonte: adaptado de Mcgarigal e Marks (1995); Volotão (1998), GOERL et al., (2011) e REMPEL et al., (2012) 

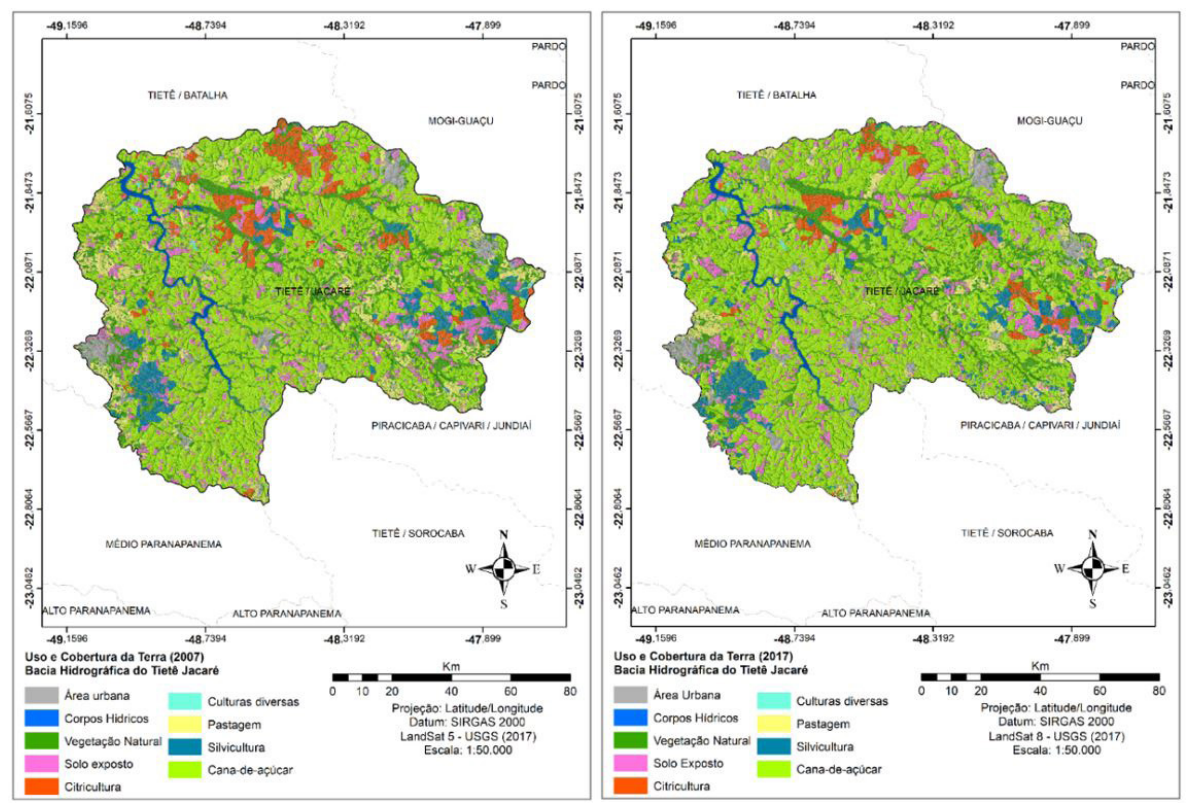

Figura 2 - Uso e cobertura da terra de 2007 e 2017 da Bacia Hidrográfica do Tietê-Jacaré.

Tabela 3 - Distribuição das classes de uso e cobertura da terra da Bacia Hidrográfica do Tietê-Jacaré em de 2007 e 2017.

\begin{tabular}{c|c|c|c|c}
\hline \multirow{2}{*}{ Classes } & \multicolumn{2}{|c|}{ Usos 2007} & \multicolumn{2}{c}{ Usos 2017 } \\
\cline { 2 - 5 } & Área (ha) & $\%$ & Área (ha) & $\%$ \\
\hline Cana-de-açúcar & $542.124,00$ & 45,90 & $607.455,00$ & 51,43 \\
\hline Corpos hídricos & $16.955,80$ & 1,44 & $16,764,60$ & 1,42 \\
\hline Citros & $62.121,90$ & 5,26 & $38.198,80$ & 3,23 \\
\hline Culturas diversas & $1.315,71$ & 0,11 & $1.382,63$ & 0,12 \\
\hline Pastagem & $76.817,59$ & 6,50 & $51.564,90$ & 4,37 \\
\hline Silvicultura & $49.272,60$ & 4,17 & $58.258,00$ & 4,93 \\
\hline Solo exposto & $122.046,00$ & 10,33 & $121.346,00$ & 10,27 \\
\hline Área urbana & $36.148,40$ & 3,06 & $43.981,07$ & 3,72 \\
\hline Vegetação & $274.288,00$ & 23,22 & $242.139,00$ & 20,50 \\
\hline Total & $1.181 .090,00$ & 100,00 & $1.181 .090,00$ & 100,00 \\
\hline
\end{tabular}

safra. As áreas de pastagem surgem em pequenas porçôes territoriais, tornando-se uma atividade voltada para subsistência ou pequena escala de produção.

A cana-de-açúcar é predominante em praticamente para todos os municípios presentes na bacia hidrográfica, porém em algumas regióes predominam também outros tipos de culturas agrícolas como a citricultura na região de Araraquara, Nova Europa e Gavião Peixoto e a silvicultura na regiáo de Agudos e Pederneiras e na regiáo de Brotas e Itirapina.

Para o ano de 2017, aproximadamente $74 \%$ da área de estudo apresentou o predomínio das atividades agrícolas sendo 607.455 ha ocupados pela cana-de-açúcar, 58.258ha por silvicultura, 51.564,9ha por pastagens, $38.198,80$ ha pela citricultura, $1.382,63$ por culturas diversas como milho, café e arroz e 121.346ha por 
solo exposto. Observa-se um crescimento de 65.331 ha dos cultivos de cana-de-açúcar, onde áreas de outros usos agrícolas foram convertidas contribuindo com o avanço do predomínio dessa cultura na região.

As áreas urbanas apresentaram-se consolidadas, com crescimento de 7.832,67ha ao longo do período de estudo (36.148,40ha em 2007 e 43.981,07ha em 2017). O crescimento urbano foi mais perceptível nos municípios de médio a grande porte, como Jáu, Bauru, São Carlos e Araraquara, onde os municípios de pequeno porte como Torrinha, Ibaté, Brotas, ainda mantém suas estruturas voltadas principalmente para as atividades contanto com suporte industrial e de bens e serviços dos municípios maiores ao redor.

Essa de predominância das atividades agrícolas e principalmente da cana-de-açúcar, coincide com o cenário paulista, sendo o estado de São Paulo, mais precisamente o interior paulista, o maior produtor de cana-de-açúcar do Brasil. Este título é devido ao crescimento do mercado interno e externo e de algumas condiçóes favoráveis ao seu cultivo, como por exemplo, ser o estado com mais terras férteis que permite a produtividade média maior do que em outras regióes e pelo fato de possuir desenvolvido setor de bens de produção para a cultura canavieira (NATALE NETTO, 2007; MARTINI et al., 2018).

O cenário observado para a Bacia Hidrográfica do Tietê-Jacaré é semelhante a estudos realizados com esta temática em diferentes regiôes (CRIUSCUOLO et al., 2006; COELHO et al., 2007; FISHER, 2008; RUDORFF et al., 2010; MORAES et al., 2013; TREVISAN, 2015) as quais também evidenciaram a expansão do cultivo da cana-de-açúcar, a conversão de outros usos agrícolas em plantio de cana-de-açúcar e a consequente supressão de áreas de vegetação nativa.

As áreas de vegetação nativa apresentam-se fragmentadas ao longo da área de estudo, como uma perda aproximadamente $2,7 \%$ em dez anos, representando uma área 32.149ha. Esses fragmentos imersos na matriz agrícola estáo em sua maioria associados a corpos hídricos que também apresentaram redução de 191,20ha das massas de águas da regiáo.

Estes remanescentes naturais localizam-se pincipalmente próximos ao Rio Tietê-Jacaré, como nos municípios de Itajú, Bariri, Ibitinga e Bocaina, próximos ao Rio Jacaré-Guaçu como nos municípios de Ribeirão Bonito, São Carlos, Ibaté e Itirapina, próximos ao Rio Jacaré-Pepira como nos municípios de Dourado e Brotas e próximos ao Rio Jaú, como nos municípios de Jaú e Mineiros do Tietê.

Essa perda de áreas de vegetação nativa foi semelhante aos estudos realizados por Moraes (2013) e Mello et al. (2014), os quais analisaram as fitofisionomias de Cerrado e Floresta Estacional Semidecidual, tipos vegetacionais presente na área de estudo. Estes estudos os autores evidenciam o processo de fragmentação da paisagem em decorrência de açóes antrópicas.

Considerando que a Mata Atlântica e o Cerrado são dois hotspots de biodiversidade, é necessária uma intervenção no processo de fragmentaçáo da paisagem, em sua maioria decorrentes do avanço da fronteira agrícola, mais especificamente pelo cultivo da cana-de-açúcar, que implica em severas mudanças nos padróes biológicos da paisagem e na conservação de fauna e flora presentes nesses habitats (MORAES et al., 2013). Estes impactos comprometem a estrutura e os serviços ambientais, como os impactos nos solos que suportam a cobertura vegetal como das maiores fontes de energia para a vida terrestre (BERTONI; LOMBARDI NETO, 2008; HERNANDEZ et al., 2015).

A ocupação desordenada da terra e o manejo inadequado do solo têm provocado diversos problemas ambientais, tais como: a compactação do solo, diminuição da quantidade de água pluvial infiltrada e o aumento do escoamento superficial. Esse conjunto de fatores propicia a intensificaçáo do processo de erosão hídrica, que pode evoluir na forma laminar, em sulco, ravina ou voçoroca (SILVA, 2001; MEDRANO; RECAMAN, 2018).

No caso do gerenciamento de bacia hidrográficas, a questão sobre o comprometimento da qualidade da água para fins de abastecimento doméstico é decorrente de poluição por diferentes fontes, tais como efluentes domésticos, efluentes industriais e deflúvio superficial urbano e agrícola. Os efluentes domésticos, por exemplo, são constituídos basicamente por contaminantes orgânicos, nutrientes e microorganismos, que podem ser patogênicos (MERTEN; MINELLA, 2002; MUSHARAFI et al., 2014).

A contaminação por efluentes industriais é decorrente das matérias-primas e dos processos industriais utilizados, A degradação dos mananciais, 
proveniente do deflúvio superficial agrícola, ocorre, principalmente, devido ao aumento da atividade primária das plantas e algas em decorrência do aporte de nitrogênio e fósforo proveniente das lavouras e da produção animal em regime confinado (MERTEN; MINELLA, 2002; MUSHARAFI et al., 2014).

O crescimento excessivo de algas e plantas reduz a disponibilidade de oxigênio dissolvido nas águas, afetando adversamente o ecossistema aquático e causando, algumas vezes, mortalidade de peixes. Além dos impactos causados aos ecossistemas aquáticos, o aumento dos níveis de nutrientes na água pode comprometer sua utilização para abastecimento doméstico, devido a alteraçóes no sabor e odor da água ou à presença de toxinas liberadas pela floração de alguns tipos de algas (SOUZA, 2005; MEDRANO; RECAMAN, 2018).

Conforme analisado na matriz de transiçáo (Tabela 4), 37,3\% da paisagem da Bacia Hidrográfica do Tietê-Jacaré foi alterada entre 2007 e 2017. As áreas de solo exposto foram as que mais sofreram alterações $(85,4 \%)$, devido as suas características de pousio para os demais usos. As características de transição foram semelhantes em todas as regióes da bacia hidrográfica, principalmente pelo predomínio das atividades relacionadas a cana-de-açúcar, o que desta forma levou os demais fragmentos da paisagem, em sua maioria, a serem convertidos para tal cultivo.

Os usos agrícolas também sofreram alteraçóes, como a citricultura $(62,7 \%)$, pastagem $(68 \%)$, silvicultura
(40,5\%) e cana-de-açúcar $(23,1 \%)$. Algumas dessas áreas ou tornaram-se áreas de pousio ou de plantio direto para o cultivo de cana-de-açúcar. As áreas naturais sofreram alteraçóes de $36,4 \%$, as quais foram convertidas entre os demais usos, entretanto algumas áreas foram recuperadas, como observado na Tabela 5 .

As transiçóes mais expressivas na região da bacia hidrográfica relacionam-se com a conversão das áreas de vegetação natural para o cultivo de cana-de-açúcar em praticamente todos os municípios integrantes da bacia hidrográfica, totalizando cerca de 60.0068 hectares em 10 anos. Entretanto, nas diversas regióes ocorreu a recuperação das áreas agrícolas para áreas de vegetação natural, embora apesar de significantes, náo ocorreu neste período a restauração ou recuperação de grandes áreas, mas sim de pequenos fragmentos ao longo de toda a paisagem.

O predomínio da cana-de-açúcar na região também fez com que os demais usos agrícolas fossem convertidos para esta cultura, como a pastagem $(33.381,30 \mathrm{ha})$, citricultura $(25.488,40 \mathrm{ha})$ e silvicultura $(6.287,50 \mathrm{ha})$. Por mais que esta atividade esteja consolidada na região, movimentando grande parte do setor econômico da região, algumas ressalvas são necessárias diante a monopolização da cultura da cana-de-açúcar, principalmente relacionadas com a conservação dos ecossistemas naturais.

Diversos autores (SANQUETTA et al., 1996; CASTRO; KAUFFMANN, 1998; AZEVEDO, 2013;

Tabela 4 - Transição das classes de uso e cobertura da terra da Bacia Hidrográfica do Tietê-Jacaré em de 2007 e 2017.

\begin{tabular}{l|r|r|r|r}
\hline \multicolumn{1}{c|}{ Matriz de transição } & Hectares em 2007 & $\begin{array}{c}\text { Hectares mantidos } \\
2017\end{array}$ & $\begin{array}{c}\text { Hectares } \\
\text { convertidos }\end{array}$ & $\begin{array}{c}\text { \% hectares } \\
\text { convertidos }\end{array}$ \\
\hline Cana-de-açúcar de açúcar & $542.124,00$ & $416.976,18$ & $125.147,82$ & 23,10 \\
\hline Corpos Hídricos & $16.955,80$ & $16.955,80$ & 0,00 & 0,00 \\
\hline Citricultura & $62.121,90$ & $23.186,10$ & $38.935,80$ & 62,70 \\
\hline Culturas diversas & $1.315,71$ & $1.300,17$ & 15,54 & 1,20 \\
\hline Pastagem & $76.817,59$ & $24.611,41$ & $52.206,18$ & 68,00 \\
\hline Silvicultura & $49.272,60$ & $29.324,90$ & $19.947,70$ & 40,50 \\
\hline Solo exposto & $122.046,00$ & $17.821,50$ & $104.224,50$ & 85,40 \\
\hline Urbano & $36.148,40$ & $36.148,40$ & 0,00 & 0,00 \\
\hline Vegetação & $274.288,00$ & $174.468,50$ & $99.819,50$ & 36,40 \\
\hline \multirow{2}{*}{ Total } & $1.181 .090,00$ & $740.792,96$ & $440.297,04$ & \multirow{2}{*}{37,30} \\
\cline { 3 - 4 } & & \multicolumn{2}{|c}{$1.181 .090,00$} & \\
\hline
\end{tabular}


Tabela 5 - Distribuição da transição das classes de uso e cobertura da terra da Bacia Hidrográfica do Tietê-Jacaré em de 2007 e 2017.

\begin{tabular}{l|c|l|c}
\hline \multicolumn{1}{c|}{ Transição (2007 - 2017) } & Área (ha) & \multicolumn{1}{c}{ Transição (2007 - 2017) } & Área (ha) \\
\hline Cana-de-açúcar - Usos diversos & 25,27 & Silvicultura - Urbano & 25,30 \\
\hline Cana-de-açúcar - Urbano & $2.286,80$ & Silvicultura - Citricultura & 930,60 \\
\hline Cana-de-açúcar - Citricultura & $5.947,89$ & Silvicultura - Pastagem & 969,90 \\
\hline Cana-de-açúcar - Pastagem & $9.947,96$ & Silvicultura - Vegetaçáo & $4.980,13$ \\
\hline Cana-de-açúcar - Silvicultura & $10.006,60$ & Silvicultura - Cana-de-açúcar & $6.287,60$ \\
\hline Cana-de-açúcar-de-açúcar - Vegetação & $37.428,80$ & Silvicultura - Solo exposto & $7.144,83$ \\
\hline Cana-de-açúcar - Solo exposto & $70.711,00$ & Silvicultura - Silvicultura & $29.324,90$ \\
\hline Cana-de-açúcar - Cana-de-açúcar & $417.474,14$ & Solo exposto - Urbano & 411,51 \\
\hline Corpos hídricos - Corpos hídricos & $16.615,35$ & Solo exposto - Pastagem & $5.890,19$ \\
\hline Citricultura - Urbano & 315,92 & Solo exposto - Citricultura & $5.931,87$ \\
\hline Citricultura - Pastagem & 630,20 & Solo exposto - Vegetaçáo & $5.949,05$ \\
\hline Citricultura - Silvicultura & $1.283,76$ & Solo exposto - Silvicultura & $6.684,18$ \\
\hline Citricultura - Vegetação & $3.003,04$ & Solo exposto - Solo exposto & $17.821,50$ \\
\hline Citricultura - Solo exposto & $8.261,57$ & Solo exposto - Cana-de-açúcar & $76.143,00$ \\
\hline Citricultura - Citricultura & $23.186,10$ & Urbano - Urbano & $3.6148,4$ \\
\hline Citricultura - Cana-de-açúcar & $25.488,40$ & Usos diversos - Usos diversos & $1.300,17$ \\
\hline Pastagem - Citricultura & 370,35 & Vegetaçáo - Citricultura & $2.169,79$ \\
\hline Pastagem - Urbano & $1.772,93$ & Vegetaçáo - Urbano & $2.848,85$ \\
\hline Pastagem - Silvicultura & $3.594,77$ & Vegetaçáo - Silvicultura & $6.619,17$ \\
\hline Pastagem - Solo exposto & $6.558,12$ & Vegetaçáo - Pastagem & $9.053,40$ \\
\hline Pastagem - Vegetação & $7.628,18$ & Vegetação - Solo exposto & $9.388,99$ \\
\hline Pastagem - Pastagem & $24.611,41$ & Vegetação - Cana-de-açúcar & $60.068,30$ \\
\hline Pastagem - Cana-de-açúcar & $33.381,30$ & Vegetação - Vegetação & $174.468,5$ \\
\hline
\end{tabular}

MACEDO et al., 2013) discutem sobre os impactos da transição dos fragmentos naturais ou mesmo agrícolas para os cultivos de cana-de-açúcar ou outras monoculturas. Como dito por Zimmermann (2009, p. 80) "a simplificação dos ecossistemas, processo indispensável para o desenvolvimento da monocultura extensiva é extremamente perigosa para a manutenção desses que, em geral, são complexos”.

\section{ANÁLISE DA REDE ESTRUTURAL DA PAISAGEM DA BACIA HIDROGRÁFICA DO TIETÊ-JACARÉ}

A Tabela 6 apresenta os indicadores gerais de fragmentação para a bacia hidrográfica nos anos de 2007 e 2017, sendo identificados 5.866 e 5.521 fragmentos respectivamente, que possuem uma densidade de 0,0050 e 0,0047 fragmentos por hectare e média de 201,17 e 213,18ha, entretanto com desvio padrão de aproximadamente 375 e 405 . Observou-se uma média de 655 e 613 fragmentos por classe de uso e cobertura da terra com área do maior fragmento ocupando aproximadamente 0,78 e $0,77 \%$ da área total da bacia.

Os indicadores de estrutura dos fragmentos, como a densidade do perímetro e índice de forma apresentam-se semelhantes entre os períodos analisados contanto com 39,73 e 38,38 e 1,81 e 1,82 em 2007 e 2017 respectivamente, o que pode estar relacionada a consolidação das atividades desenvolvidas na região assim como da organização e distribuição dos fragmentos na paisagem.

A diminuição do número de fragmentos, assim como o aumento do tamanho médio dos mesmos são derivados principalmente do crescimento das matrizes agrícolas com consequente diminuição da diversificação de fragmentos das classes de uso e cobertura da terra na região da área 
Tabela 6 - Índices de fragmentação da Bacia Hidrográfica do Tietê-Jacaré em de 2007 e 2017.

\begin{tabular}{l|c|c}
\hline \multicolumn{1}{c|}{ Índice } & $\mathbf{2 0 0 7}$ & $\mathbf{2 0 1 7}$ \\
\hline Área total dos fragmentos (ha) & $1.181 .090,00$ & $1.181 .090,00$ \\
\hline Área média dos fragmentos (ha) & 201,35 & 213,93 \\
\hline Declividade média & 6,37 & 6,37 \\
\hline Densidade de fragmentação (nf/ha) & 0,0050 & 0,0047 \\
\hline Densidade do perímetro & 39,73 & 48,38 \\
\hline Desvio padráo da área média dos fragmentos & 375,60 & 1,82 \\
\hline Indicador médio de forma & 1,81 & 0,77 \\
\hline Índice de maior fragmento (\%) & 0,78 & 613,88 \\
\hline Média de fragmentos por classe & 655,33 & $5.521,00$ \\
\hline Número total de fragmentos & $5.866,00$ & $8.574,47$ \\
\hline Perímetro médio (borda) & $7.999,73$ & \\
\hline
\end{tabular}

de estudo, como foi evidenciado nas análises de dinâmica temporal. Em contrapartida, o grau de fragmentaçáo da classe de vegetaçáo aumentou, totalizando 2.190 e 2.231 fragmentos, área média de 125,25 e 108,53ha e desvio padrão de 250,87 para 256,16 em 2007 e 2017 respectivamente (Tabela 7 e Figura 3).

Em relação à análise do número de fragmentos e da área média por classe de uso houve também o predomínio das áreas agrícolas, tendo a canade-açúcar novamente como principal atividade, totalizando 1.331 e 1.361 fragmentos com médias de 407,31 e 446,33 ha e desvio padrão 444,07 e 484,17 em 2007 e 2017 respectivamente. Este fato também ocorre com a Área Relativa Ocupada que indicou o quanto os fragmentos de cada classe ocupam em relação relativos à área e ao número total de fragmentos, a qual teve predomínio das regióes de silvicultura com 2,35 e 1,20 e cana-de-açúcar de 2,02 e 2,09.

$\mathrm{At}=$ área total; $\mathrm{Am}=$ área média; $\mathrm{DF}=$ Densidade de fragmentação; NTF; Número total de fragmentos; $\mathrm{ARO}=$ Área relativa ocupada DMC $=$ Declividade média por classe; IMF = Índice do maior fragmento; $\mathrm{DP}$ = densidade do perímetro; DesvP = Desvio padrão; índice de forma; $\mathrm{PM}=$ Perímetro médio

A relação entre a área relativa ocupada o número total de fragmentos permitiu estimar o grau de fragmentação de cada classe de uso e cobertura da terra. As áreas urbanas, com poucos fragmentos e baixa área relativa ocupada, sáo exemplos característicos de fragmentos que se aglomeram em diversos conglomerados ao longo da área de estudo, diferente do comportamento das áreas de cana-de-açúcar que possuem alta quantidade de fragmentos com alta aérea relativa ocupada, o que é observado com a dissolução e predomínio de tal atividade ao longo de toda a bacia hidrográfica.

Assim como para a bacia hidrográfica como um todo, as classes de uso e cobertura da terra apresentaram altos valores de índice de Forma entre 1,5 e 2 (conforme REMPEL et al., 2012, quanto mais próximo de 1 , menor o efeito de borda). A Densidade de Fragmentação por Classe indicou o número de fragmentos em relação à área por classe de uso e cobertura da terra, em que, quanto maior o seu valor, maior o número de fragmentos em relação à área, e quanto maior a área e menor o número de fragmentos, menor a densidade de fragmentação.

Toda a bacia hidrográfica apresentou baixa densidade de fragmentação, devido a sua extensão territorial, com 0.0050 e 0.0047 em 2007 e 2017. Tal densidade de fragmentação pode estar relacionada ao predomínio das matrizes agrícolas com grandes fragmentos e também pela resoluçáo da classificação do uso e cobertura da terra, realizada na escala 1:50.000, que pode ter inibido a real fragmentação dentro da divisão das regiôes analisadas.

Por meio da análise do indicador "Declividade Média por Classe de Uso e cobertura da terra” foi possível determinar a capacidade potencial dos fragmentos de cada classe se conectar com os fragmentos à jusante. Segundo Goerl et al. (2011) esta conexão pode se dar principalmente pela propagação de fluxo superficial via mecanismos de geração de escoamento, bem 
Tabela 7 - Índices de fragmentação por classe de uso e cobertura da terra Bacia Hidrográfica do Tietê-Jacaré em de 2007 e 2017.

\begin{tabular}{|c|c|c|c|c|c|c|c|c|}
\hline \multirow{2}{*}{ Classes de usos/ Índice } & \multicolumn{4}{|c|}{ AT } & \multicolumn{2}{|c|}{$\mathrm{AM}$} & \multicolumn{2}{|c|}{$\mathrm{DF}$} \\
\hline & \multicolumn{2}{|c|}{2007} & \multicolumn{2}{|c|}{2017} & 2007 & 2017 & 2007 & 2017 \\
\hline Área urbana & \multicolumn{2}{|c|}{$36.148,40$} & \multicolumn{2}{|c|}{$43.981,07$} & 187,30 & 193,75 & 0,00534 & 0,00516 \\
\hline Corpos hídricos & \multicolumn{2}{|c|}{$16.955,80$} & \multicolumn{2}{|c|}{$16.764,60$} & 66,49 & 70,14 & 0,015 & 0,014 \\
\hline Vegetação & \multicolumn{2}{|c|}{$274.288,00$} & \multicolumn{2}{|c|}{$242.139,00$} & 125,25 & 108,53 & 0,0080 & 0,0092 \\
\hline Solo exposto & \multicolumn{2}{|c|}{$122.046,00$} & \multicolumn{2}{|c|}{$121.346,00$} & 88,38 & 125,49 & 0,0011 & 0,0080 \\
\hline Citricultura & \multicolumn{2}{|c|}{$38.198,80$} & \multicolumn{2}{|c|}{$62.121,90$} & 381,99 & 913,56 & 0,0016 & 0,0018 \\
\hline Culturas diversas & \multicolumn{2}{|c|}{$1.315,71$} & \multicolumn{2}{|c|}{$1.382,63$} & 263,14 & 276,53 & 0,0038 & 0,0036 \\
\hline Pastagem & \multicolumn{2}{|c|}{$76.817,59$} & \multicolumn{2}{|c|}{$51.564,90$} & 250,22 & 261,75 & 0,0040 & 0,0038 \\
\hline Silvicultura & \multicolumn{2}{|c|}{$49.272,60$} & \multicolumn{2}{|c|}{$58.258,00$} & 473,78 & 257,78 & 0,0021 & 0,0039 \\
\hline Cana-de-açúcar & \multicolumn{2}{|c|}{$542.124,00$} & \multicolumn{2}{|c|}{$607.455,00$} & 407,31 & 446,33 & 0,00075 & 0,00074 \\
\hline \multirow{2}{*}{ Classes de usos/ Índice } & \multicolumn{2}{|c|}{ NTF } & \multicolumn{2}{|c|}{ ARO } & \multicolumn{2}{|c|}{$\mathrm{DMC}$} & IN & $\mathrm{IF}$ \\
\hline & 2007 & 2017 & 2007 & 2017 & 2007 & 2017 & 2007 & 2017 \\
\hline Área urbana & 193 & 227 & 0,93 & 0,91 & 5,80 & 5,87 & 10,82 & 9,60 \\
\hline Corpos hídricos & 255 & 239 & 0,33 & 0,33 & 3,85 & 3,65 & 53,77 & 54,39 \\
\hline Vegetação & 2190 & 2231 & 0,62 & 0,51 & 7,69 & 7,76 & 1,33 & 2,94 \\
\hline Solo exposto & 1381 & 967 & 0,44 & 0,59 & 6,56 & 6,63 & 0,11 & 1,83 \\
\hline Citricultura & 100 & 68 & 1,90 & 4,27 & 6,63 & 6,66 & 7,33 & 16,19 \\
\hline Culturas diversas & 5 & 5 & 1,31 & 1,29 & 6,44 & 6,40 & 30,69 & 32,47 \\
\hline Pastagem & 307 & 197 & 1,24 & 1,22 & 6,84 & 6,91 & 3,36 & 6,32 \\
\hline Silvicultura & 104 & 226 & 2,35 & 1,20 & 6,53 & 7,06 & 6,81 & 5,50 \\
\hline Cana-de-açúcar & 1331 & 1361 & 2,02 & 2,09 & 6,70 & 6,80 & 0,73 & 0,68 \\
\hline cses de & & & & & & & $\mathrm{PI}$ & $M$ \\
\hline Classes de u & 2007 & 2017 & 2007 & 2017 & 2007 & 2017 & 2007 & 2017 \\
\hline Área urbana & 1,02 & 1,14 & 523,30 & 522,03 & 1,48 & 1,47 & 6.287 & 5934 \\
\hline Corpos hídricos & 0,69 & 0,67 & 678,52 & 667,86 & 1,42 & 1,76 & 3.229 & 3323 \\
\hline Vegetação & 14,50 & 14,29 & 250,87 & 256,16 & 2,06 & 2,07 & 7.821 & 7568 \\
\hline Solo exposto & 4,97 & 4,29 & 144,85 & 183,25 & 1,58 & 1,50 & 4.255 & 5240 \\
\hline Citricultura & 1,22 & 0,72 & 723,50 & 814,20 & 1,81 & 1,59 & 14.454 & 12527 \\
\hline Culturas diversas & 0,038 & 0,037 & 149,57 & 160,10 & 1,65 & 1,60 & 9.075 & 8930 \\
\hline Pastagem & 2,55 & 1,58 & 339,04 & 353,11 & 1,88 & 1,83 & 9.806 & 9445 \\
\hline Silvicultura & 1,01 & 1,42 & 564,57 & 469,64 & 1,83 & 1,48 & 11.339 & 7392 \\
\hline Cana-de-açúcar & 13,68 & 14,21 & 444,07 & 484,17 & 1,84 & 1,76 & 12.137 & $12.338,2$ \\
\hline
\end{tabular}

como o tipo de matéria produzido pelos fragmentos a montante, como, por exemplo o carreamento de poluentes de forma difusa, resinas ácidas e sedimentos gerados via processos erosivos.

A bacia hidrográfica do Tietê-Jacaré apresentou declividade média homogenia ao longo das classes de uso e cobertura da terra, tendo como esperado, as áreas de corpos hídricos com os mais baixos índices. Este fato indica uma interconexão entre os tipos de uso e cobertura da terra, que implica nas diversas possibilidades de impactos ou de influências das regióes, umas com as outras.

O processo de alteração da paisagem conforme analisado na Bacia Hidrográfica do Tietê-Jacaré, também foi notado em estudos de outras regiōes (SOARES FILHO, 2001; CHAVES; SANTOS, 2009; SILVA et al., 2017) os quais observaram o processo 


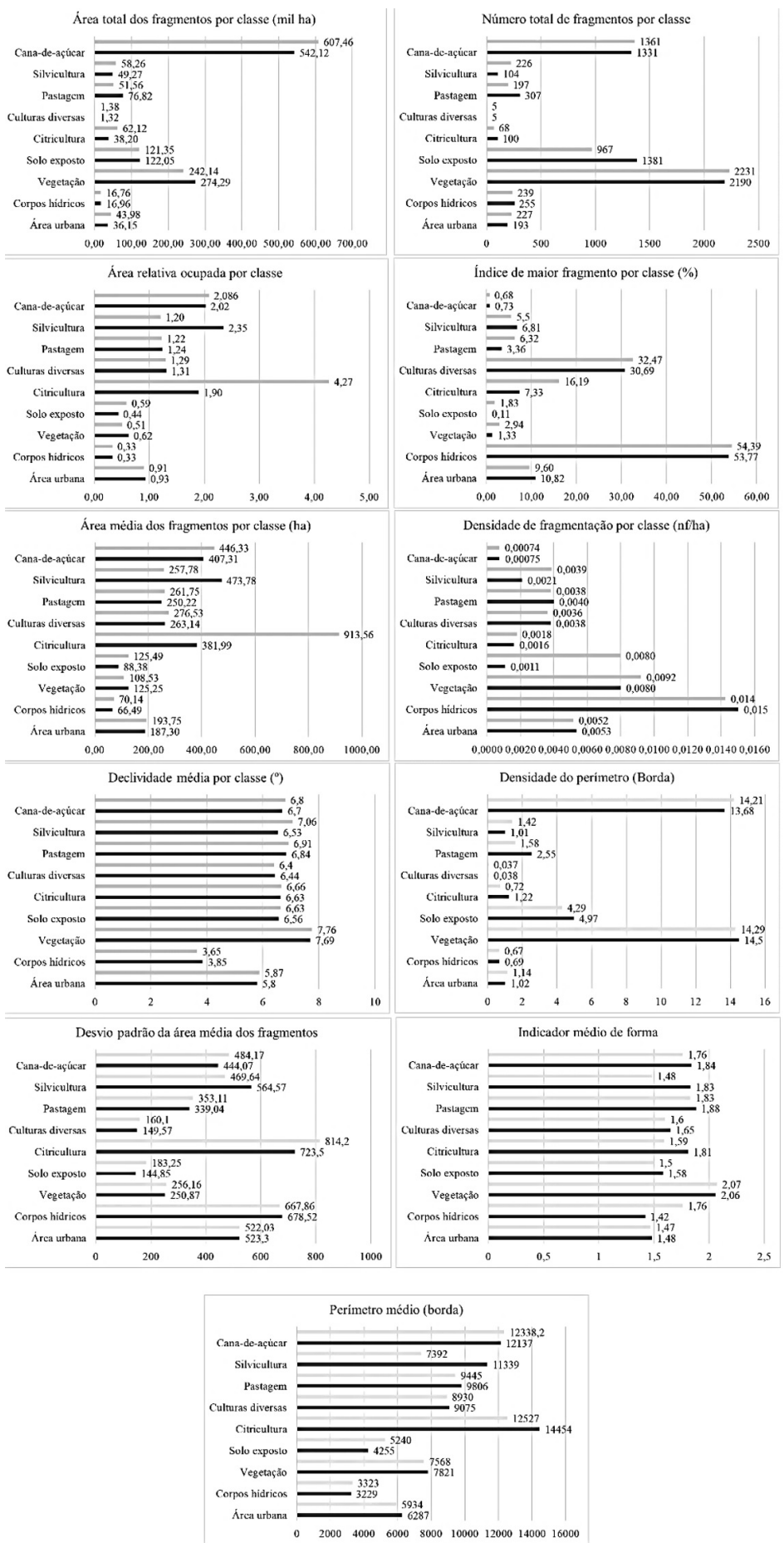

Figura 3 - Resultados dos Índices de fragmentação para a Bacia Hidrográfica do Tietê- Jacaré. 
de fragmentação das áreas naturais, assim como dos impactos acarretados pelas atividades antrópicas.

Oliveira et al. (2014) objetivaram mapear a cobertura da terra e analisar as métricas de fragmentação da paisagem da bacia hidrográfica do Alto São Bartolomeu - Distrito Federal do Brasil, o quais evidenciaram que a maioria dos fragmentos remanescentes de vegetaçáo nativa encontraram-se pressionados pela matriz agrícola em funçáo do acelerado processo de ocupação do solo em seu entorno, nem sempre planejado e organizado.

\section{CONSIDERAÇÓES FINAIS}

A região da Bacia Hidrográfica do Tietê-Jacaré possui um alto potencial para o desenvolvimento de atividades agrícolas, as quais foram confirmadas pela classificação do uso e cobertura da terra que demonstrou o predomínio de tais atividades em todas as regióes da bacia.

Faz-se essencial a preocupação não apenas da condiçáo atual da regiáo, mas com as tendências que se solidificam ao passar dos anos, como as perdas de áreas naturais e das mudanças do padrão e organização da paisagem em decorrência da expansão das atividades antrópicas. Os ecossistemas, com seus bens e serviços ambientais, subsidiam diversas atividades antrópicas e socioeconômicas, e quando sobrecarregados além de sua capacidade suporte, podem comprometer o atendimento das necessidades humanas.
A bacia hidrográfica apresentou uma redução de sua qualidade ambiental e aumento do predomínio das atividades antrópicas que consequentemente culminaram com mudanças nos padróes de conectividade ou fragmentação, onde as áreas urbanas e a cana-de-açúcar são predominantes nessas interconexóes. Esta preponderância deve-se ser observada de forma mais detalhada no que tange o planejamento da bacia hidrográfica, principalmente relacionado os possíveis impactos acarretados por estes.

Os índices de fragmentação, ao expressarem o estado de configuraçáo das paisagens, apresentaram-se como ferramentas importantes no diagnóstico voltado a conservação dos ecossistemas, possibilitando uma análise precisa dos elementos que as compóe. Tais índices permitiram também a comparação não apenas dos fragmentos naturais, mas de todas as classes de uso e cobertura da terra, o que essencial no planejamento regional, como o caso de bacia hidrográficas.

Entretanto, atenta-se que as análises de fragmentação devem ser sempre contextualizadas e suas discussóes devem ser embasadas de acordo com a escala de análise, pois esta pode implicar nas mudanças de observação dos estudos.

\section{AGRADECIMENTOS}

Este trabalho foi financiado pela Fundação de Amparo à Pesquisa do Estado de São Paulo (FAPESP) processo 2015/19918-3.

\section{REFERÊNCIAS}

ADAMCZYK, J.; TIEDE, D. Zonal metrics: a python toolbox for zonal landscape structure analysis. Computers \& Geosciences, v. 99, p. 91-99, 2017.

AZEVEDO, T. N. Efeito da expansão do cultivo de cana-de-açúcar na composição da paisagem do estado de São Paulo. 2013. 79 f. Dissertação (Mestado em Biociências) - Universidade de São Paulo, 2013.

BERTONI, J.; LOMBARDI NETO, F. Conservação do solo. 6. ed. São Paulo: Ícone, 2008. 355p.

BOSCOLO, D.; FERREIRA, P. A.; LOPES, L. E. Da matriz a matiz: em busca de uma abordagem funcional para a ecologia de paisagens. Filosofia e História da Biologia, v. 11, p. 157-187, 2016.

CABACINHA, C. D.; CASTRO, S. S.; GONÇALVES, D. A. Análise da estrutura da paisagem da alta bacia do Rio Araguaia na savana brasileira. Revista Floresta, v. 40, p. 675-690, 2010. 
CALEGARI, L. et al. Análise da dinâmica de fragmentos florestais no município de Carandaí, MG, para fins de restauração florestal. Revista Árvore, v. 34, n. 5, p. 871-880, 2010.

CASTRO, E. A.; KAUFFMANN, J. B. Ecosystem structure in the Brazilian Cerrado: a vegetation gradient of aboveground biomass, root mass and consumption by fire. Journal of Tropical Ecology, v. 14, p. 263-283, 1998.

CHALFOUN, A. D.; THOMPSON III, F. R.; RATNASWAMY, M. J. Nest predators and fragmentation: a review and meta-analysis. Conservation Biology, v. 16, p. 306-318, 2002.

CHAVES, H. M. L.; SANTOS, L. B. Ocupação do solo, fragmentação da paisagem e qualidade da água em uma pequena bacia hidrográfica. Revista Brasileria de Engenharia Agrícola e Ambiental, v. 13, n. 6, p. 922-930, 2009.

COELHO, A. T. et al. Sustentabilidade da expansão da cultura canavieira. Cadernos Técnicos da Associação Nacional de Transportes Públicos, São Paulo, v. 6, p. 1-13, 2007.

COMITÊ DAS BACIAS HIDROGRÁFICAS DA SERRA DA MANTIQUEIRA - CBH-SM. Unidade de gerenciamento de recursos hídricos. 2015. Disponível em: <https://www.comitesm.sp.gov.brlinstitucional.php?k=ugrhi>. Acesso em: 12 fev. 2018.

CRIUSCUOLO, C. et al. Dinâmica de uso e cobertura das terras na região nordeste do Estado de São Paulo. 1. ed. Campinas: Embrapa Monitoramento por Satélite, 2006. v. 1.

D'EON, R. G. et al. Landscape connectivity as a function of scale and organism vagility in a real forested landscape. Conservation Ecology, v. 6, p. 1-10, 2002.

ETTO, T. L. et al. Ecologia da paisagem de remanescentes florestais na Bacia Hidrográfica do Ribeirão das Pedras - Campinas-SP. Revista Árvore, v. 37, p. 1063-1071, 2013.

EUROPARC. Conectividad ecológica y áreas protegidas. herramentas y casos practicos. 1. ed. Fundación Interuniversitaria Fernando González Bernáldez para los Espacios Naturales, 2009. v. 2.

FAHRIG, L. Effect of habitat fragmentation on the extinction treshold: a synthesis. Ecological Applications, v. 12, p. 346-353, 2002.

FAHRIG, L. Effects of Habitat Fragmentation on Biodiversity. Annual Review of Ecology and Systematics, v. 34, p. 487-515, 2003.

FISHER, G. Land use dynamics and sugarcane production. In: Zuurbier, P.; Van De Vooren, J. (Eds.). Sugarcane ethanol: contributions to climate change mitigation and the environment. Wageningen Academic Publishers, 2008. p. 29-62.

GIBBS, J. P.; STANTON, E. J. Habitat fragmentation and arthropod community change: carrion beetles, phoretic mites, and flies. Ecological Applications, v. 11, p. 79-85, 2001.

GOERL, R. F. et al. Elaboração e aplicação de índices de fragmentação e conectividade da paisagem para análise de bacias hidrográficas. Revista Brasileira de Geografia Física, v. 5, p. 1000-1012, 2011.

GUIMARÃES, T. F. R. Conectividade e padrões de riqueza e diversidade de espécies de peixes nas lagoas do litoral norte do Rio Grande do Sul, Brasil. 2009. 40 f. Monografia (Graduação em Ciências Biológicas) - Universidade Federal do Rio Grande do Sul, 2009. 
HADDAD, N. M. et al. Habitat fragmentation and its lasting impact on Earth's ecosystems. Science Advances, v. 1, n. 2, p. 1-9, 2015.

HERNANDEZ, R. R. et al. Solar energy development impacts on land cover change and protected areas. Proceedings of the National Academy of Sciences of the United States of America, v. 112, p. 13579-13584, 2015.

INSTITUTO BRASILEIRO DE GEOGRAFIA E ESTATÍSTICA - IBGE. Cartas planialtimétricas. 1971. Disponível em: <ftp://geoftp.ibge.gov.br/ cartas_e_mapas/folhas_topograficas/editoradas/escala_50mil/>. Acesso em: 12 fev. 2018.

INSTITUTO BRASILEIRO DE GEOGRAFIA E ESTATÍSTICA - IBGE. Manual técnico de uso da terra. 3. ed. 2013. Disponivel em: <www.ibge. gov.br/home/geociencias/recursosnaturais/usodaterra/manual_usodaterra.shtm>. Acesso em: 12 fev. 2018.

LORONI, M. L. Conectividade e redes ecológicas em paisagens fragmentadas: aplicações em conservação da biodiversidade e restauração ecológica. 2015. Disponivel em: <https://www.criandoelo.com.br/wp-content/uploads/2015/10/Maria-Lucia-Lorini.pdf>. Acesso em: 12 fev. 2018.

MACEDO, R. C. et al. Modelagem dinâmica espacial das alterações de cobertura e uso da terra relacionadas à expansão canavieira. Boletim de Ciências Geodésicas, v. 19, p. 313-337, 2013.

MADUREIRA, H. Infraestrutura verde na paisagem urbana contemporânea: o desafio da conectividade e a oportunidade da multifuncionalidade. Revista da Faculdade de Letras - Geografia - Universidade do Porto, v. 1, p. 33-43, 2012.

MARTINI, D. Z. et al. Land availability for sugarcane derived jet-biofuels in São Paulo—Brazil. Land Use Policy, v. 70, p. 256-262, 2018.

MCGARIGAL, K.; MARKS, B. J. FRAGSTATS: spatial pattern analysis program for categorical maps: user manual. 1995. v. 2.0.

MEDINI, G. F.; VIEIRA, M. V. Conectividade funcional e a importância da interação organismo paisagem. Oecol, v. 11, n. 4, p. 493-502, 2007.

MEDRANO, L.; RECAMAN, L. Space and society in the 21st century - The case of São Paulo. Bitácora Urbano Territorial, v. 28, p. 69-81, 2018.

MELLO, K. et al. Cenários ambientais para o ordenamento territorial de áreas de preservação permanente no município de Sorocaba, SP. Revista Árvore, v. 38, p. 309-317, 2014.

MERTEN, G. H.; MINELLA, J. P. Qualidade da água em bacias hidrográficas rurais: um desafio atual para a sobrevivência futura. Agroecologia e Desenvolvimento Rural Sustentável, v. 3, n. 4, p. 33-36, 2002.

MONTANHEIRO, F.; KIANG, C. G. Nitrato no aquífero adamantina: o caso do município de Monte Azul Paulista, SP. Revista do Instituto Geológico, São Paulo, v. 37, n. 2, p. 25-44, 2016.

MONTEIRO, J. F. et al. Modelling the effect of riparian vegetation restoration on sediment transport in a human-impacted Brazilian catchment. Ecohydrology, v. 9, n. 7, p. 1289-1303, 2016.

MORAES, M. C. P. Dinâmica da paisagem da zona de amortecimento do Parque Estadual de Porto Ferreira, SP. 2013. 92 f. Dissertação (Mestrado em Sustentabilidade na Gestão Ambiental) - Universidade Federal de São Carlos, Sorocaba, 2013. 
MORAES, M. C. P.; TOPPA, R. H.; MELLO, K. A expansão da cana-de-açúcar como fator de pressão para áreas naturais protegidas. In: SANTOS, J. E.; ZANIN, E. M. (Orgs.). Faces da polissemia da paisagem: ecologia, planejamento e percepção. 1. ed, São Carlos: Rima, 2013. p. 163-173. v. 5.

MUSHARAFI, S. K.; MAHMOUD, I. Y.; BAHRY, S. N. Environmental contamination by industrial effluents and sludge relative to heavy metals. Journal of Geoscience and Environment Protection, v. 2, p. 14-18, 2014.

NATALE NETTO, J. A saga do álcool:fatos e verdades sobre os 100 anos do álcool combustível em nosso país. 1. ed. Osasco: Novo Século, 2007.

OLIVEIRA, C. H.; SANTOS, J. E.; TOPPA, R. H. Efeitos do uso do solo urbano na qualidade ambiental e de vida, na vegetação e na impermeabilização do solo. In: SANTOS, J. E. et al. (Org.). Faces da polissemia da paisagem. 1. ed. São Carlos: Rima, 2004. p. 585-619. v. 2.

OLIVEIRA, F. R. et al. Análise da fragmentação da paisagem da bacia hidrográfica do Alto São Bartolomeu como subsídio ao modelo pressãoestado-resposta. L'Espace Geographique, v. 17, p. 207-234, 2014.

REMPEL, R. S.; KAUKINEN, D.; CARR, A. P. Patch analyst and patch grid. Thunder Bay, Ontario: Ministry of Natural Resources: Centre for Northern Forest Ecosystem Research, 2012.

RUDORFF, B. F. T. et al. Studies on the rapid expansion of sugarcane for ethanol production on São Paulo State (Brazil) using Landsat Data. Remote Sensing, v. 2, n. 4, p. 1057-1076, 2010.

SANQUETTA, C. R. et al. Matriz de transição para simulação da dinâmica de florestas naturais sob diferentes intensidades de corte. Ciência Florestal, v. 6, n. 1, p. 65-78, 1996.

SÃO PAULO. Lei Estadual n. 7.663 de 30/12/1991. Estabelece normas de orientação à Política Estadual de Recursos Hídricos bem como ao Sistema Integrado de Gerenciamento de Recursos Hídricos. Diário Oficial [da] República Federativa do Brasil. 1991. Disponivel em: <https:I/ www.al.sp.gov.br/repositorio/legislacao/lei/1991/lei-7663-30.12.1991.html>. Acesso em: 12 fev. 2018.

SÃO PAULO. Lei Estadual n. 9.034 de 27/12/1994. Dispõe sobre o Plano Estadual de Recursos Hídricos - PERH, a ser implantado no período 1994 e 1995, em conformidade com a Lei 7663, de 30/12/91, que instituiu normas de orientação à Política Estadual de Recursos Hídricos. Diário Oficial [da] República Federativa do Brasil. 1994. Disponivel em: <https://www.al.sp.gov.br/repositorio/legislacao/lei/1994/lei-9034-27.12.1994. html >. Acesso em: 12 fev. 2018.

SILVA, D. P. etal. Efeitos da fragmentação florestal no município de Japurá - Paraná. Revista GEOMAE, v. 8, p. 186-195, 2017. Número especial.

SILVA, M. S. F.; SOUZA, R. M. Spatial patterns of forest fragmentation in the Flona lbura - Sergipe. Mercator, Fortaleza, v. 13, n. 3, p. 121-137, 2014.

SILVA, V. C. Erosão atual, erosão potencial e aporte de sedimento na Bacia do rio Paracatu (MG/GO/DF). 2001. 108 f. Tese (Doutorado em Geociências) - Instituto de Geociências, Universidade de Brasília, Brasilia, 2001.

SOARES FILHO, B. S. Fragmentação da paisagem florestal em função da estrutura e dinâmica fundiária no norte do Mato Grosso. In:X SBSR, 10., 2001, Foz do Iguaçu. Anais... Foz do Iguaçu: INPE, 2001. p. 987-995.

SOUZA, R. A. D. Avaliação das frações de fosfato como indicadores de eutofrização de águas superficiais. 2005. 124 f. Dissertação (Mestrado em Agronomia) - Universidade federal de Lavras, 2005. 
TREVISAN, D. P. Análise das variáveis ambientais causadas pelas mudanças dos usos e cobertura da terra do município de São Carlos, São Paulo, Brasil. 2015. 80 f. Dissertação (Mestrado em Ciências Ambientais) - Universidade Federal de São Carlos, São Carlos, 2015.

TUNDISI, J. G. et al. A bacia hidrográfica do Tietê-Jacaré: estudo de caso em pesquisa e gerenciamento. Estudos Avançados, v. 22, n. 63, p. $159-172,2008$.

UNITED STATES GEOLOGICAL SURVEY - USGS. Scientific agency for natural sciences. 2017. Disponivel em: <https://earthexplorer.usgs. gov/>. Acesso em: 27 mar. 2019. Imagens LandSat - 5 abr. 2007; 8 mar. 2017.

VOLOTÃO, C. F. S. Trabalho de análise espacial: métricas do Fragstats. São José dos Campos: INPE, 1998.

WU, J.; ROBBS, R. Key issue and research priority in landscape ecology. An idiosyncratic synthesis. Landscape Ecology, v. 17, p. 355-365, 2002.

ZIMMERMANN, C. L. Monocultura e transgenia: impactos ambientais e insegurança alimentar. Veredas do Direito., v. 6, n. 12, p. 79-100, 2009.

Diego Peruchi Trevisan

Universidade Federal de São Carlos UFSCar; Programa de Pós-Graduação em

Ciências Ambientais (Doutorado). Departamento de Ciências Ambientais, São Carlos-SP, Brasil. email: diego.peruchi@gmail.com

Contribuição do autor

Pesquisa realizada como parte de estudo de projeto de doutorado do autor.

Luiz Eduardo Moschini Universidade Federal de São Carlos UFSCar; Programa de Pós-Graduação em Ciências Ambientais (Orientador); Departamento de Ciências Ambientais (Professor Adjunto); São Carlos-SP, Brasil. email: lemoschini@ufscar.br

Contribuição do autor

Orientador do autor 01; participação na coleta de campo; participaçáo na análise dos dados e escrita do artigo. 